\title{
Preparos minimamente invasivos para solução cosmética de manchamento por tetraciclina: relato de caso
}

\author{
Minimally invasive procedures for cosmetic solution for tetracycline staining: \\ case report
}

\author{
Preparos mínimamente invasivos para resolución estética de manchas \\ ocasionadas por tetraciclina: reporte de caso
}

\author{
Adriana Cristina ZAVANELLI ${ }^{\mathbf{1}}$ \\ Ricardo Alexandre ZAVANELLI ${ }^{2}$ \\ José Vitor Quinelli MAZARO ${ }^{3}$ \\ Luciene Milazzo MACHADO ${ }^{4}$ \\ Rogerio de Alencastro COSTA ${ }^{5}$ \\ Carolina de Assis Barros BRITO ${ }^{6}$ \\ ${ }^{l}$ Cirurgiã-Dentista, Especialista em Prótese Dentária, \\ Mestrado e Doutorado em Reabilitação Oral pela Faculdade de Odontologia de Ribeirão Preto - USP, \\ Professora Doutora da Disciplina de Prótese Parcial Fixa do Departamento de Materiais Odontológicos e Prótese \\ da Faculdade de Odontologia de Araçatuba - FOA-Unesp \\ ${ }^{2}$ Cirurgião-Dentista, Especialista em Prótese Dentária e Implantodontia, \\ Mestrado e Doutorado pela Faculdade de Odontologia de Piracicaba - Unicamp, \\ Pós-Doutorado em Biomateriais pela New York University College of Dentistry, \\ Professor Doutor Associado da Disciplina de Prótese Dentária do Departamento de Reabilitação Oral \\ da Faculdade de Odontologia da Universidade Federal de Goiás \\ ${ }^{3}$ Cirurgião-Dentista, Especialista em Prótese Dentária, \\ Mestrado e Doutorado em Prótese Dentária pela Faculdade de Odontologia de Araçatuba - Unesp, \\ Professor Doutor da Disciplina de Prótese Parcial Fixa do Departamento de Materiais Odontológicos e Prótese \\ da Faculdade de Odontologia de Araçatuba - FOA-Unesp \\ ${ }^{4}$ Cirurgião-Dentista, Graduada pela Universidade Paulista de Goiás, Especialista em Prótese Dentária - IKO \\ ${ }^{5}$ Cirugião-Dentista, Graduado pela Universidade do Oeste Paulista, Unoeste, Campus Presidente Prudente, Especialista em Prótese Dentária-IKO \\ ${ }^{6}$ Cirurgiã-Dentista, Especialista em Implantodontia, Mestre em Reabilitação Oral pela Faculdade de Odontologia de Araraquara - UNESP e \\ Professora Mestre da Disciplina de Clinica Integrada da Universidade Paulistal Campus Goiânia - UNIP
}

\begin{abstract}
Resumo
Atualmente a estética tem sido o principal motivo pelo qual diversos pacientes buscam o consultório odontológico para tratamento protético reabilitador. Nesse contexto, os laminados ou facetas cerâmicas são uma modalidade restauradora de abordagem minimamente invasiva, que apresenta resultados estéticos e longevos. Assim, o objetivo deste artigo foi de relatar um caso com o uso de laminados cerâmicos confeccionados em IPS e.max (IvoclarVivadent) para a restauração de dentes manchados por tetraciclina. O manchamento causado pela tetraciclina exibe variados graus de comprometimento (grau I, II, III e IV) exigindo abordagem específica para cada ocorrência. O caso clínico em questão abordou o planejamento e protocolo clínico de execução para a resolução estética de manchamento por tetraciclina grau III. Com o relato e execução das restaurações minimamente invasivas deste caso, pode-se concluir que a determinação do grau de comprometimento do manchamento é que ditará a quantidade necessária de desgaste e o tipo de restauração indireta minimamente invasiva. Também se pode concluir que todas as etapas de execução clínica e laboratorial são essenciais para o sucesso do resultado estético, destacando-se o sistema cerâmico indireto a ser selecionado e a cor do agente cimentante.
\end{abstract}

Descritores: Cerâmica: Reabilitação Bucal; Estética Dentária.

\begin{abstract}
Currently aesthetics has been the main reason why many patients seek dental office for prosthetic rehabilitation treatment. In this context, laminates or ceramic veneers are restorative form of minimally invasive approach, which has aesthetic and long-lived results. The objective of this article was to report a case with the use of ceramic laminates made of IPS e.max (IvoclarVivadent) for the restoration of teeth stained by tetracycline. The staining caused by tetracycline exhibits varying degrees of severity (grade I, II, III and IV) requiring specific approach for each occurrence. The clinical case in question addressed the planning and execution of clinical protocol for aesthetic resolution staining tetracycline grade III. With the running account of minimally invasive and restores this case, it can be concluded that the determination of the staining degree is compromised will dictate the necessary amount of wear and the type of minimally invasive indirect restoration. One can also conclude that all stages of clinical and laboratory executions are essential to the success of the cosmetic result, highlighting the indirect ceramic system to be selected and the color of the cement agent.

Descriptors: Ceramics; Mouth Rehabilitation; Esthetics, Dental.
\end{abstract}

\section{Resumen}

Actualmente la estética ha sido la razón principal por la que muchos pacientes buscan consultorio dental para el tratamiento de rehabilitación bucal. En este contexto, carillas de cerámica muestran enfoque mínimamente invasivo y tiene resultados estéticos con larga vida. Este caso tuvo como objetivo presentar el uso de carillas de cerámica realizadas con IPS e.max (IvoclarVivadent) para la restauración de los dientes manchados por tetraciclina. Las manchas ocasionadas por exposiciones de tetraciclina presentan diversos grados de gravedad (grado I, II, III y IV) que exijan un enfoque específico para cada caso. El caso clínico en cuestión se dirigió a la planificación y ejecución del protocolo clínico para la resolución estética de dientes teñidos por tetraciclina grado III. Se puede concluir que el grado de tinción dictará la cantidad necesaria de desgaste y el tipo de restauración indirecta mínimamente invasiva. También se puede concluir que todas las etapas de la ejecución clínica y de laboratorio son esenciales para el éxito de lo resultado cosmético, destacando el sistema de cerámica indirecta a ser seleccionado y el color del agente de cemento.

Descriptores: Personal de Odontología en Hospital; Higine Bucal; Salud Bucal; Manifestaciones Bucales. 


\section{INTRODUÇÃO}

A alteração de cor dos elementos dentários pode ocorrer no período de sua formação embrionária e também ao longo da vida por fatores intrínsecos e/ou extrínsecos. As principais alterações de cor associadas ao manchamento dentário de origem intrínseca podem ser as congênitas, como por exemplo, hipoplasia de esmalte e amelogênese imperfeita, ou as adquiridas, como as alterações provocadas pela ingestão do antibiótico tetraciclina. Já o manchamento de origem extrínseca, tem ocorrência mais frequente, podendo ser observado nas alterações de cor provocadas pelo uso de cigarros e corantes de alimentos entre outros ${ }^{1}$.

A tetraciclina pode provocar o manchamento dentário durante a formação embrionária pela utilização do medicamento pela gestante, ou ainda no período da amamentação. A administração deste antibiótico para crianças também pode ser crítica no período de três a cinco meses até os sete anos de idade.

A dentina é a estrutura dentária mais afetada pela tetraciclina, porém no esmalte este medicamento pode se ligar ao cálcio alterando assim a cor destes tecidos também.

Lacerda et al. ${ }^{2}$ citaram que os manchamentos por tetraciclina são classificados em grau I, grau II, grau III e grau IV dependendo da extensão, localização e profundidade da alteração de cor. A presença de manchas azuladas ou cinza escuras em faixas ou bandas caracterizam o presente caso clínico, classificado como manchamento grau III.

A repercussão estética para o sorriso do paciente nesta ocorrência (grau III) é considerada importante sendo o facetamento a solução cosmética e biológica mais indicada para os dentes afetados, uma vez que procedimentos não invasivos como clareamento não apresenta resultados satisfatórios.

Assim, o objetivo deste trabalho foi de apresentar o protocolo clínico do planejamento à cimentação para a resolução estética em dentes acometidos por manchas de tetraciclina grau III.

\section{CASO CLÍNICO}

Paciente V.S.F., gênero feminino, 34 anos de idade, procurou atendimento odontológico no curso de especialização em Prótese Dentária do Instituto Kenedy de Odontologia - Goiânia, tendo como queixa principal o manchamento em todos os elementos dentais em decorrência do uso indiscriminado de antibiótico à base de tetraciclina durante a infância (Figuras 1 e 2).

Após exame clínico e radiográfico, o manchamento dentário apresentado pela paciente foi caracterizado como grau III. Deste modo, os procedimentos de clareamento foram descartados e o planejamento da resolução estética selecionado foi a confecção de laminados ou facetas cerâmicas confeccionadasem dissilicato de lítio, sistema IPS e.max (IvoclarVivadent) para corrigir a cor e modificara forma dos dentes de acordo com a queixa da paciente para deixá-los mais femininos e delicados.

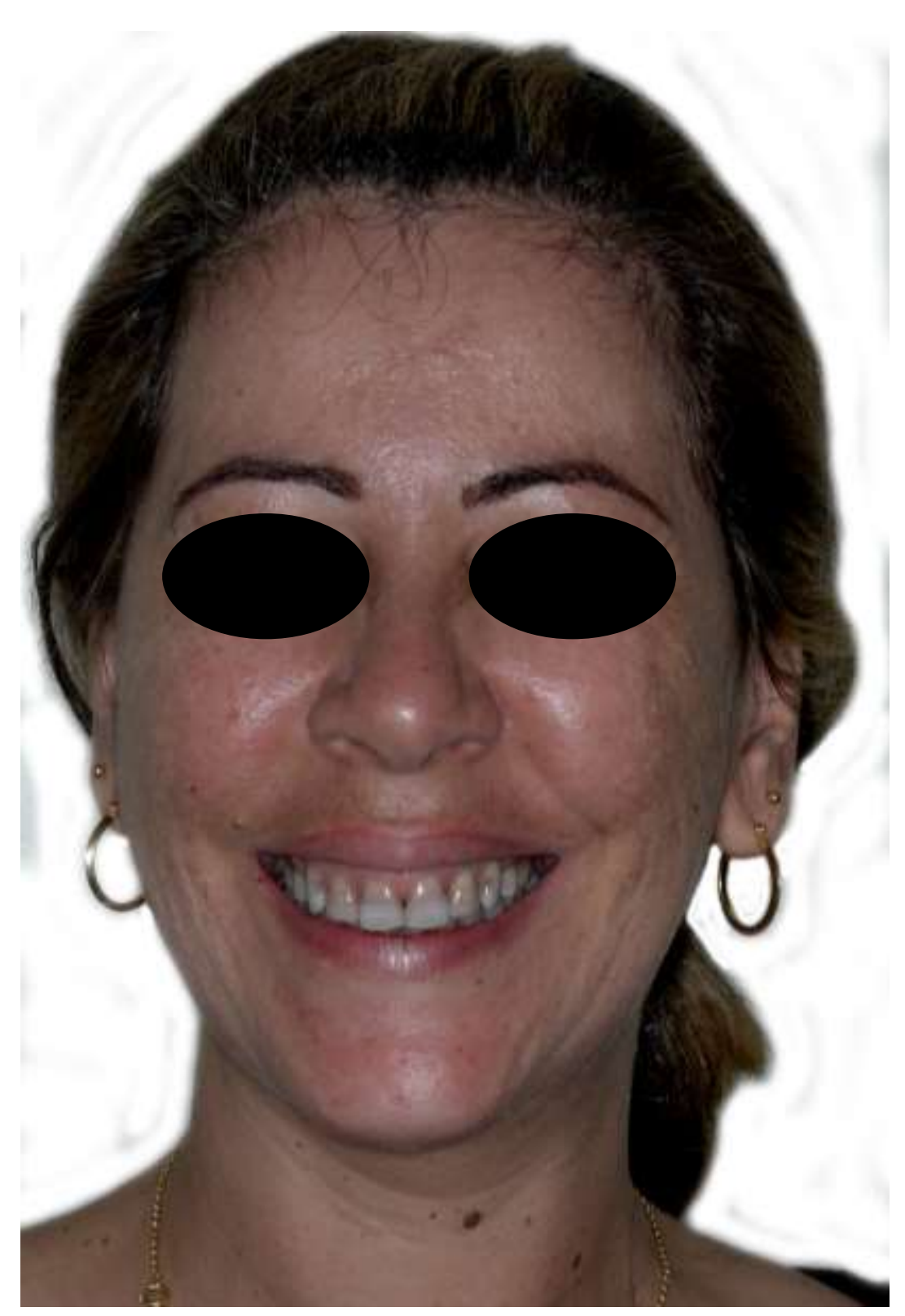

Figura 1. Vista frontal da paciente

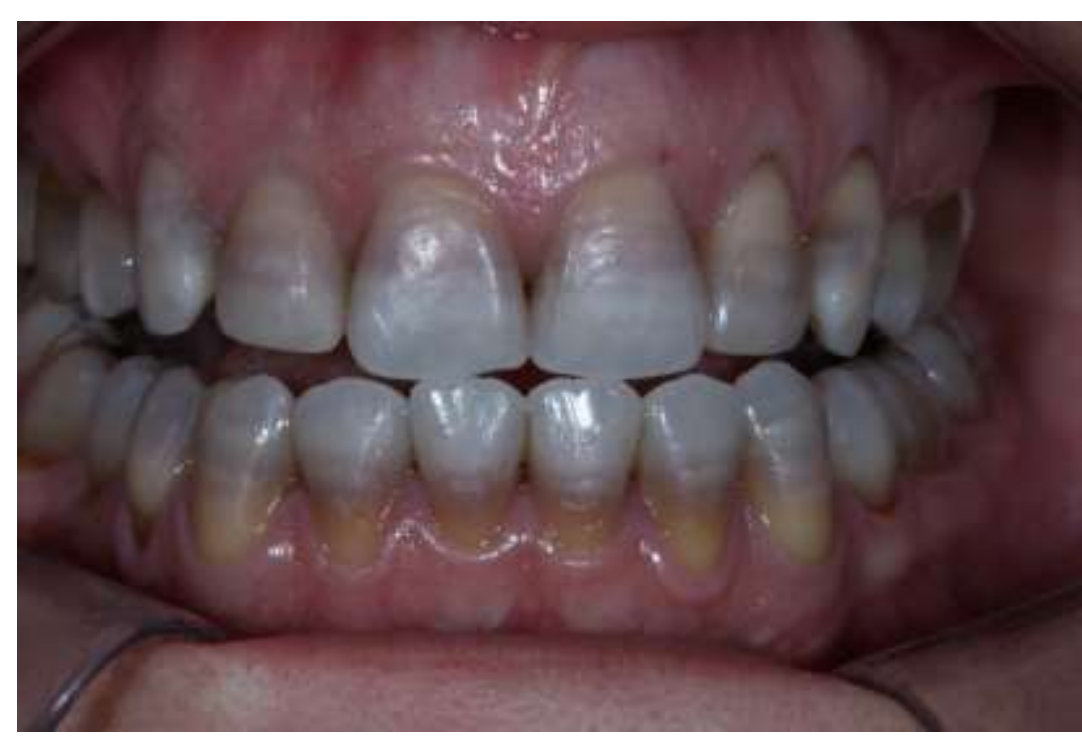

Figura 2. Close up do sorriso evidenciando o manchamento dos elementos dentais superiores e inferiores

Foram realizadas as moldagens de estudo do arco superior e inferior com silicone de adição Express XT (3M Espe) e enviados ao laboratório juntamente com as fotografias para a elaboração do enceramento diagnóstico (Figura 3).

Sobre o enceramento diagnóstico foram confeccionados dois guias de silicone de condensação 
Zetaplus (Zhermack). Um guia de silicone foi recortado próximo ao contorno cervical para a realização do ensaio estético (Figuras 4 e 5) e o segundo guia de silicone foi recortado próximo às bordas incisais e oclusais dos dentes superiores e separado em duas metades para atuar durante os preparos como orientação dos desgastes vestibulares e incisais/oclusais.

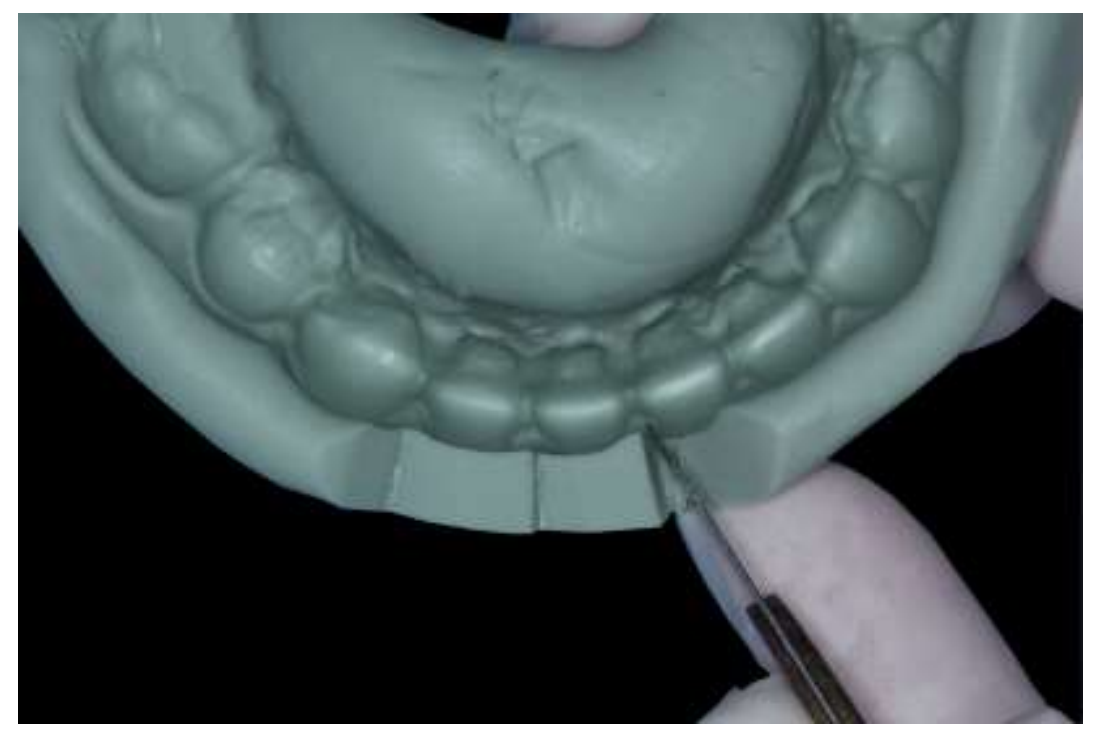

Figura 3. Enceramento diagnóstico

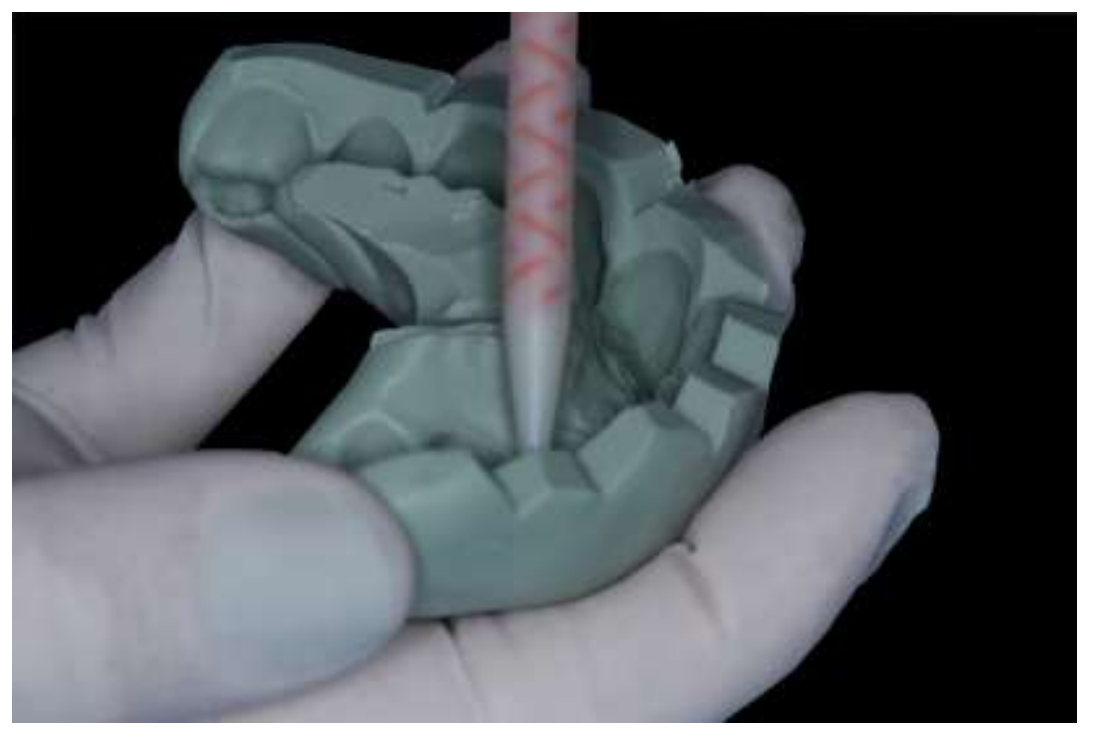

Figura 4. Recorte do guia de silicone utilizado para mock up

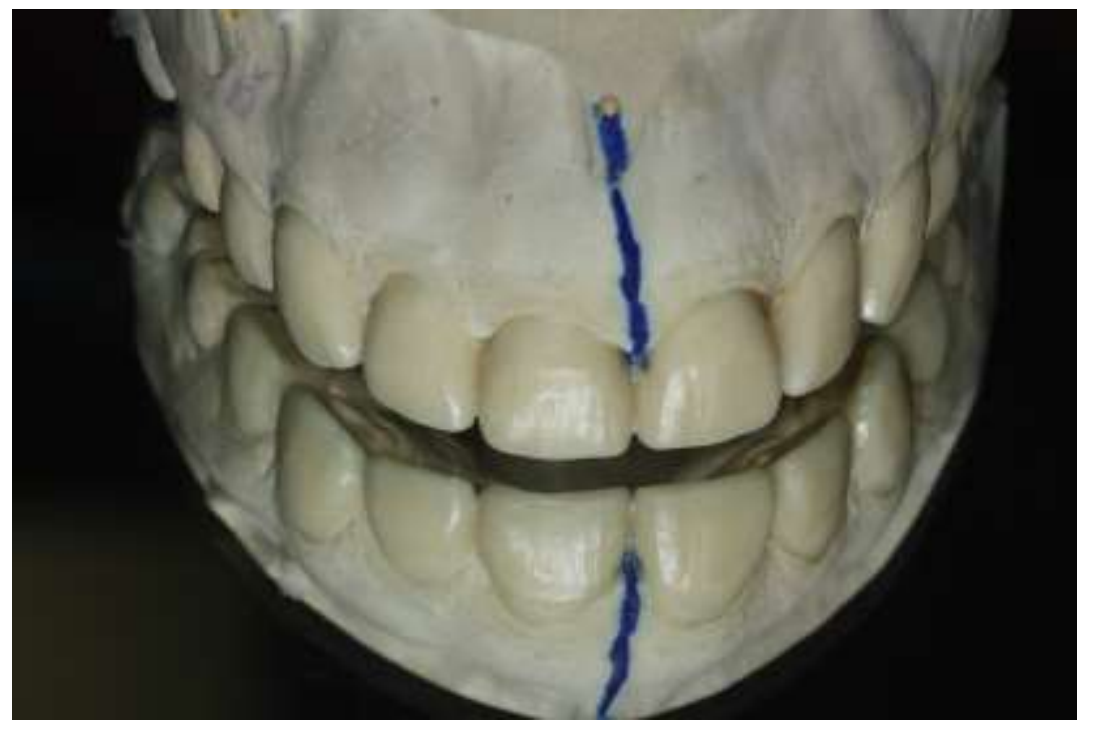

Figura 5. Inserção da resina bisacrílica no guia de silicone

Na Figura 6, pode-se observar a pré-visualização do resultado final do tratamento por meio do mock up. Foi avaliado o suporte labial, o contorno dentário, o comprimento dos dentes e a altura/largura dos elementos em relação aos lábios em repouso e durante o sorriso. Neste momento, foi observado que o tratamento realmente deveria alcançar até os primeiros molares, visto que na avaliação em posições dinâmicas estes dentes estavam à mostra mesmo a uma distância social.

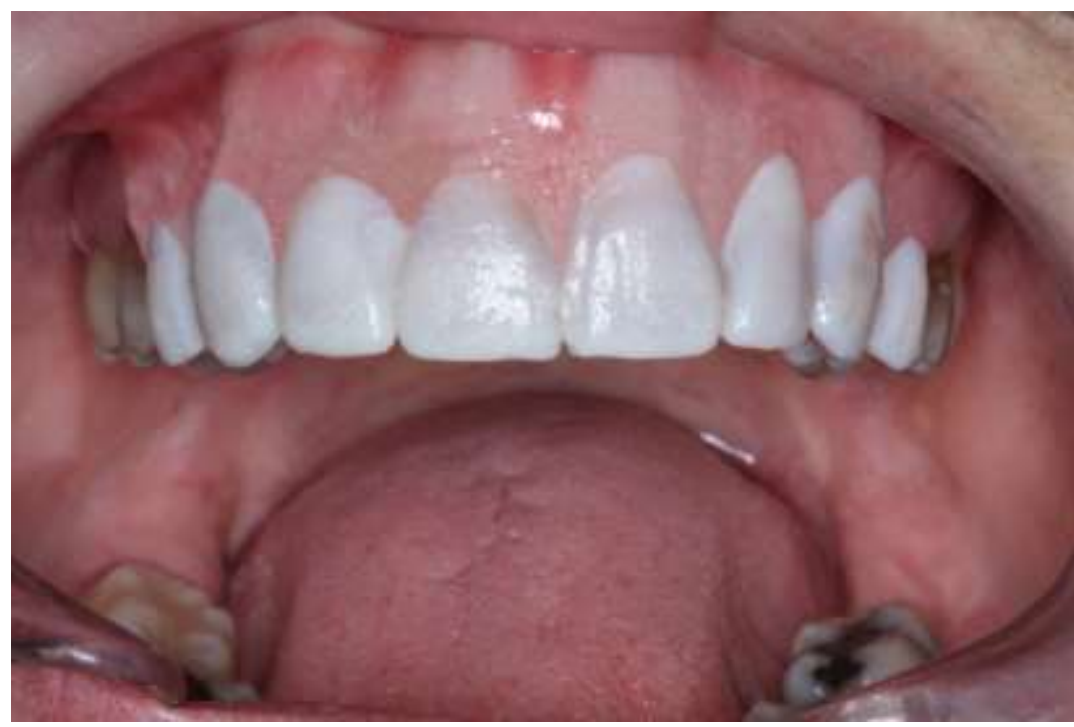

Figura 6. Vista do sorriso com o mock up

Após aprovação da paciente, iniciaram-se as etapas dos preparos minimamente invasivos com auxílio daponta diamantada anelada 4142 (KG Sorensen) realizou-se as canaletas horizontais na face vestibular do dente, respeitando-se os planos cervical, médio e incisal/oclusal (Figuras 7 e 8).

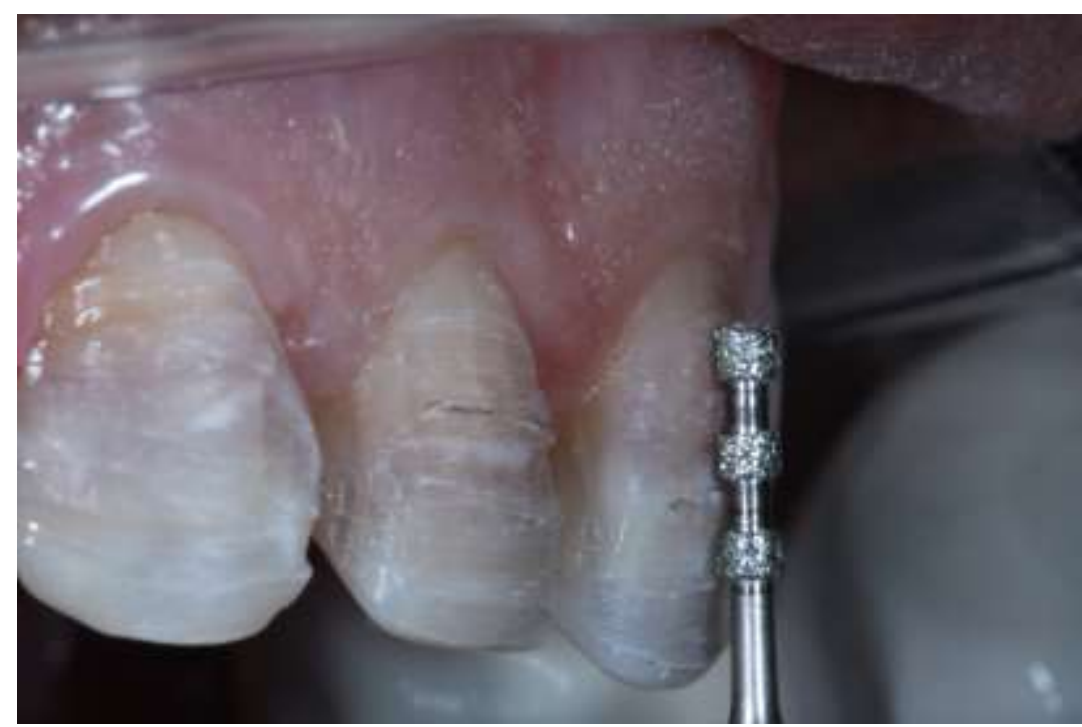

Figura 7. Posicionamento da ponta diamantada 4121 no plano cervical

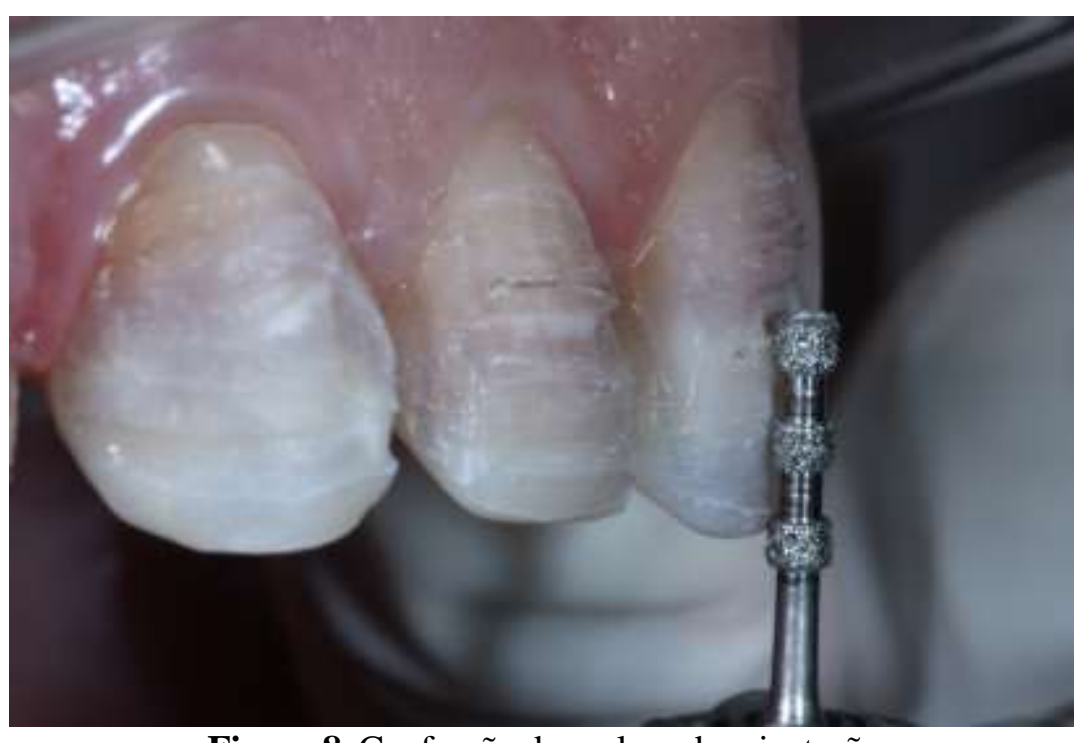

Figura 8. Confecção dos sulcos de orientação na face vestibular com ponta 4142

Em seguida, com a ponta diamantada troncocônica 4138 (KG Sorensen) foram confeccionados sulcos de orientação na superfície incisal/oclusal (Figura 9). Com esta mesma ponta realizou a união dos sulcos de orientação posicionados na face vestibular. A regularização e acabamento dos preparos (Figura 10) 
foram realizados com ponta diamantada 2135F (KG Sorensen) e discos soflex (3M Espe).

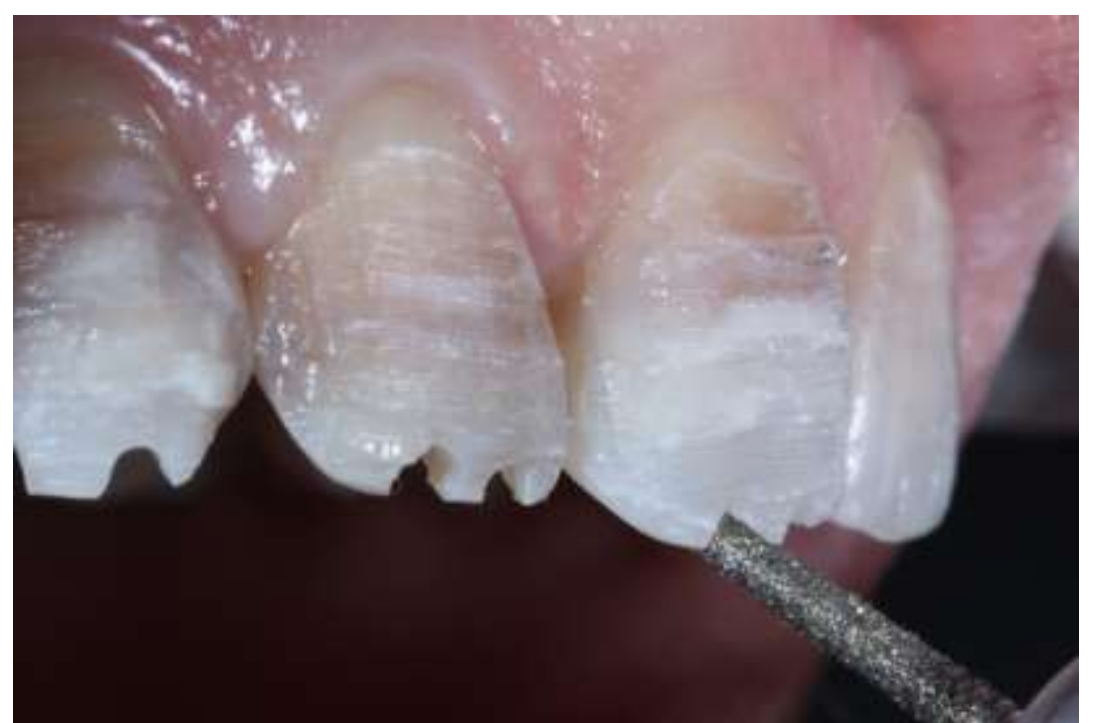

Figura 9. Confecção dos sulcos de orientação nas superfícies incisais

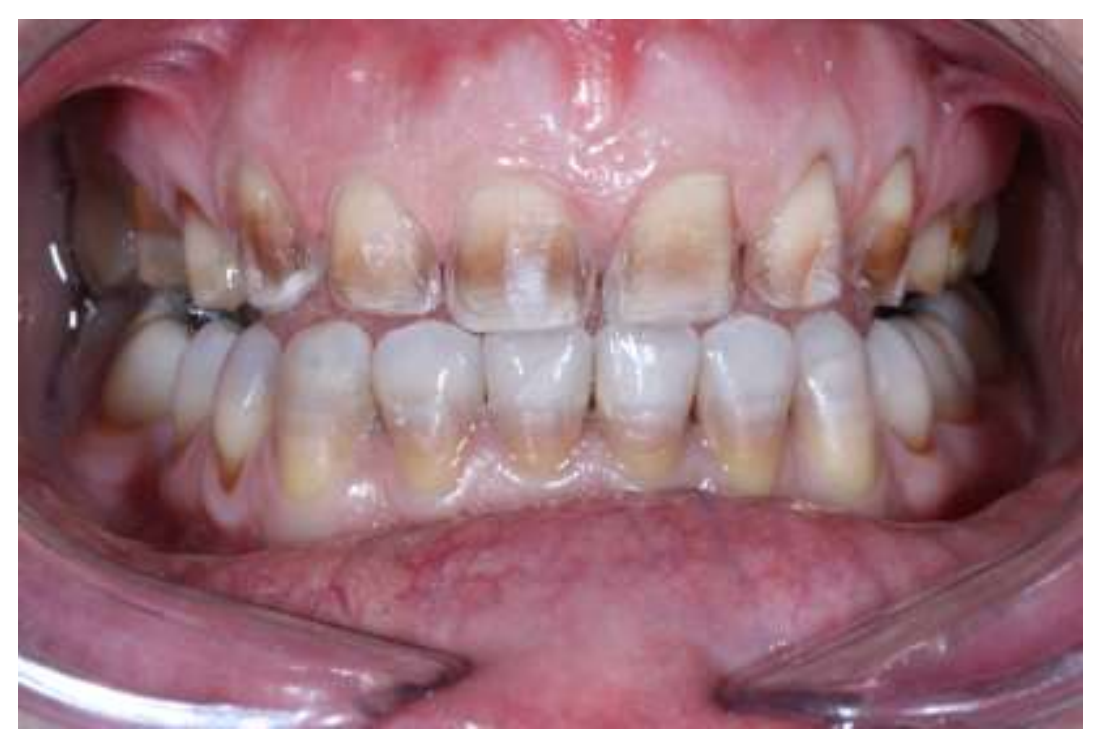

Figura 10. Preparos finalizados

O passo seguinte foi executar a técnica de moldagem, etapa fundamental para o sucesso de um trabalho protético restaurador indireto. Dentre as técnicas possíveis, foi selecionada a técnica do duplo fio e da dupla mistura também conhecida como reembasamento. Deste modo o fio Ultra-Pack de numeração \#000 (Ultradent) impregnado com cloreto de alumínio (Hemostop, Dentsply) foi inserido no sulco gengival com auxílio da espátula 171 (Ultradent). Um segundo fio (Ultra-Pack de numeração \#00) sem substância hemostática, foi inserido sobre o primeiro (Figuras 11 e 12).

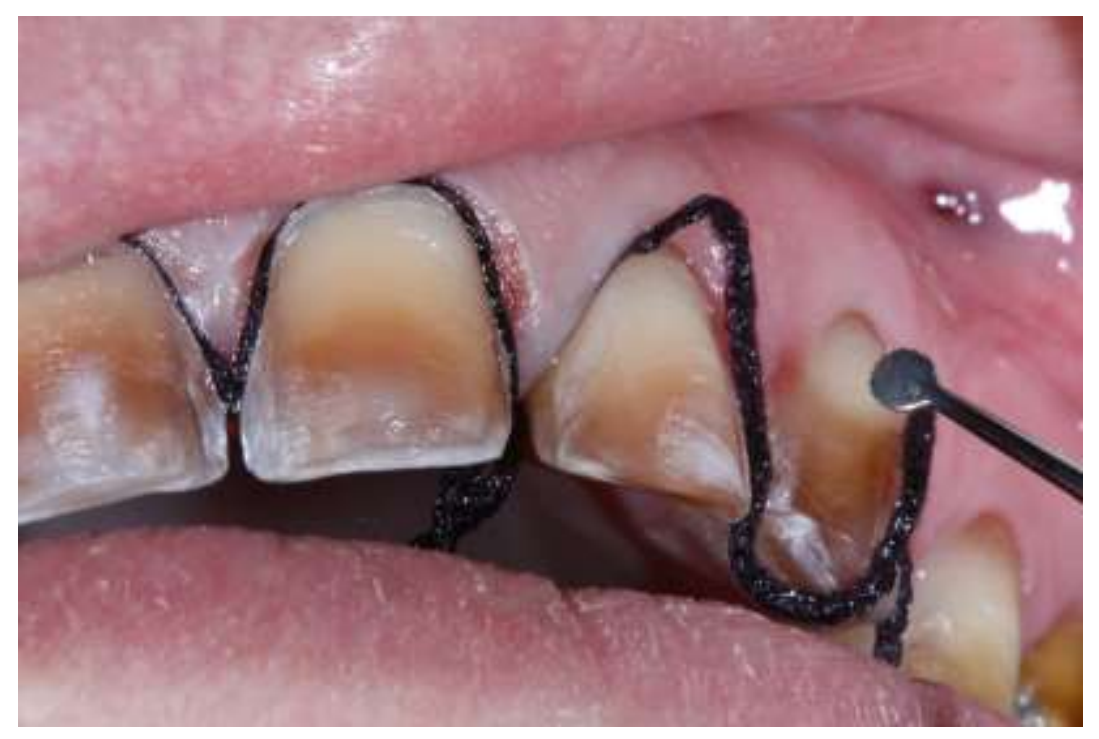

Figura 11. Inserção do fio retrator \#000 no sulco gengival

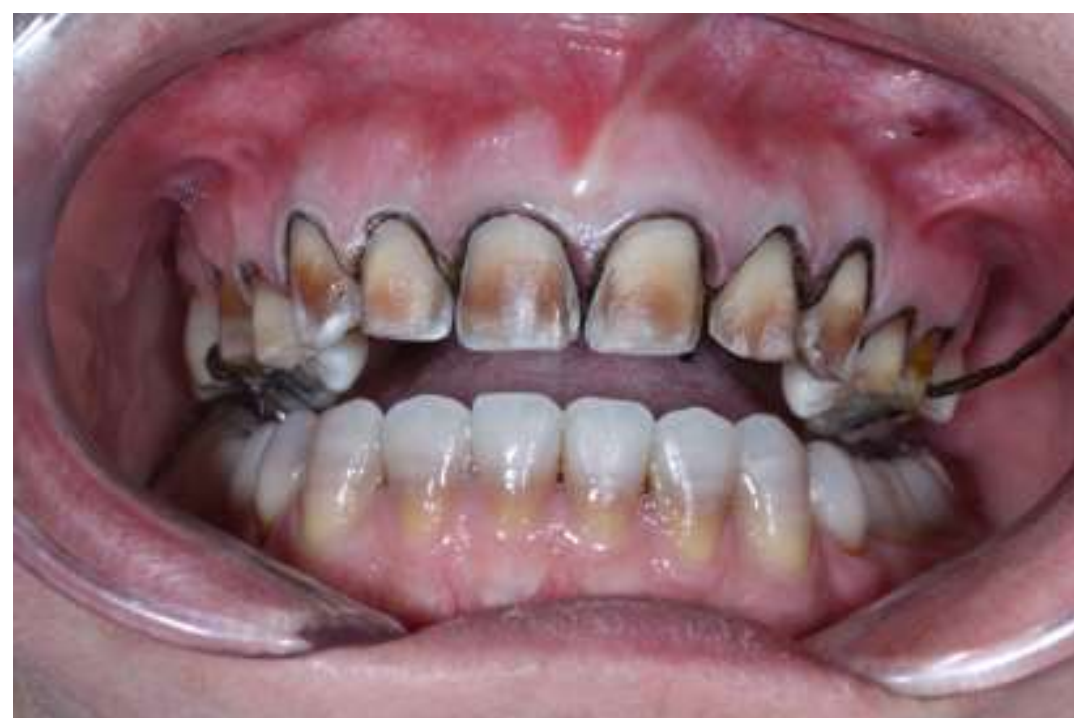

Figura 12. Inserção do fio retrator \#00 sobre o primeiro fio

Decorridos 5 minutos após a inserção dos fios de afastamento, a moldeira previamente selecionada foi carregada com o silicone de adição de consistência pesada (Express XT, 3M Espe). O espaço para o material de moldagem de consistência leve foi previsto já neste momento, colocando sobre o material carregado na moldeira uma folha plástica, conhecido como espaçador. O conjunto foi inserido no arco superior da paciente e aguardou-se sua reação de polimerização. Após remoção do molde, foi removido o segundo fio retrator e injetado o silicone de adição de consistência leve (Express XT, 3M Espe) sobre os dentes preparados na boca do paciente, e sobre o material de consistência pesada existente na moldeira já com o espaço (Figura 13).

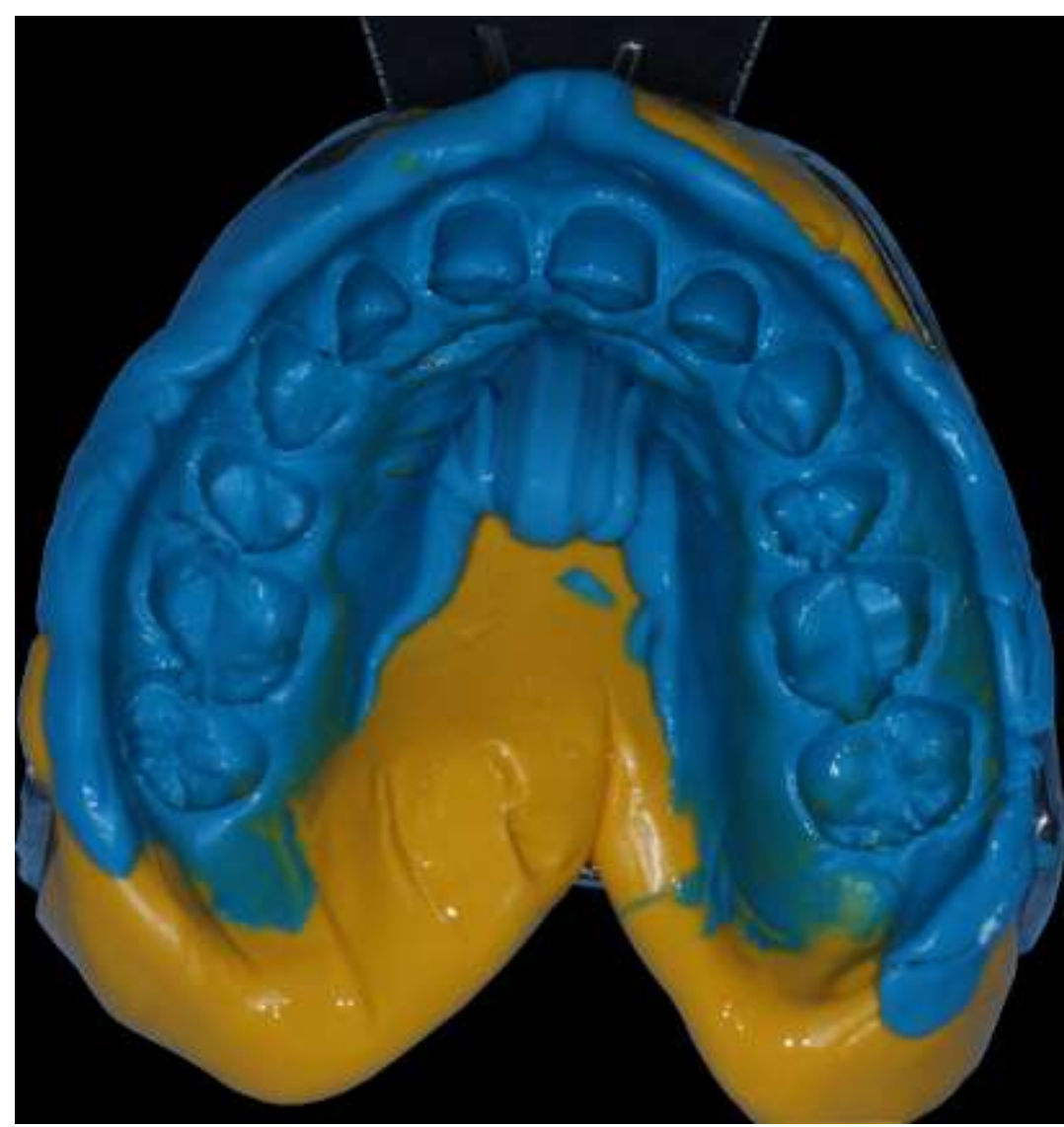

Figura 13. Sequência da moldagem executada pela técnica do reembasamento ou dupla mistura

Os moldes, o registro oclusal e registro da tomada de cor (Figura 14) foram enviados ao laboratório para confecção dos laminados cerâmicos. O material selecionado foi o dissilicato de lítio IPS e.max (Ivoclar, Vivadent) injetado e estratificado. 


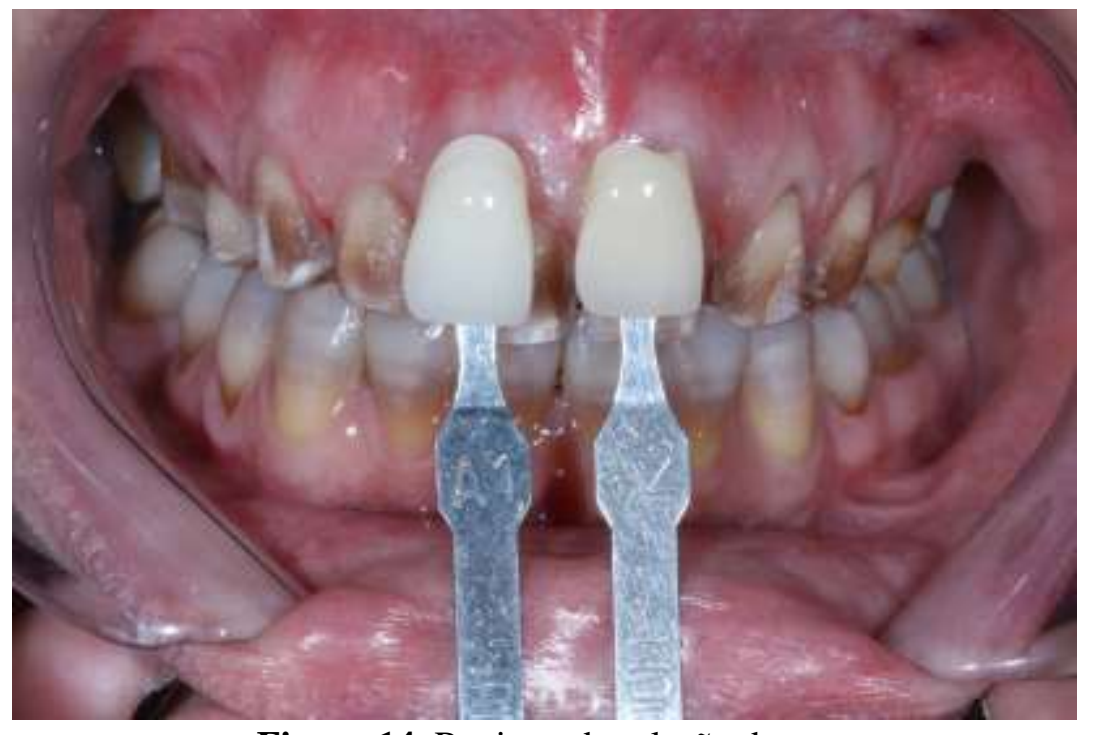

Figura 14. Registro da seleção de cor

As restaurações provisórias foram confeccionadas a partir do enceramento e preenchimento do guia de silicone com resina bisacrílica Protemp4 (3M Espe).

Com os laminados concluídos, iniciou-se a etapa da cimentaçãodas peças protéticas (Figura 15). Para a determinação da cor do cimento, realizou-se uma prova com as pastas try in do cimento resinoso Variolink II (Ivoclar,Vivadent). A cor selecionada foi o transparente. Verificada adaptação e ajuste das peças, suas superfícies internas foram condicionadas com ácido fluorídrico a 10\% durante 20 segundos, lavadas e secas. Em seguida aplicou-se o ácido fosfórico a $37 \%$ durante por 1 minuto (para a remoção dos debris da cerâmica), lavadas e secas e aplicado silano durante 1 minuto. As peças receberam jato de ar quente durante 2 minutos.
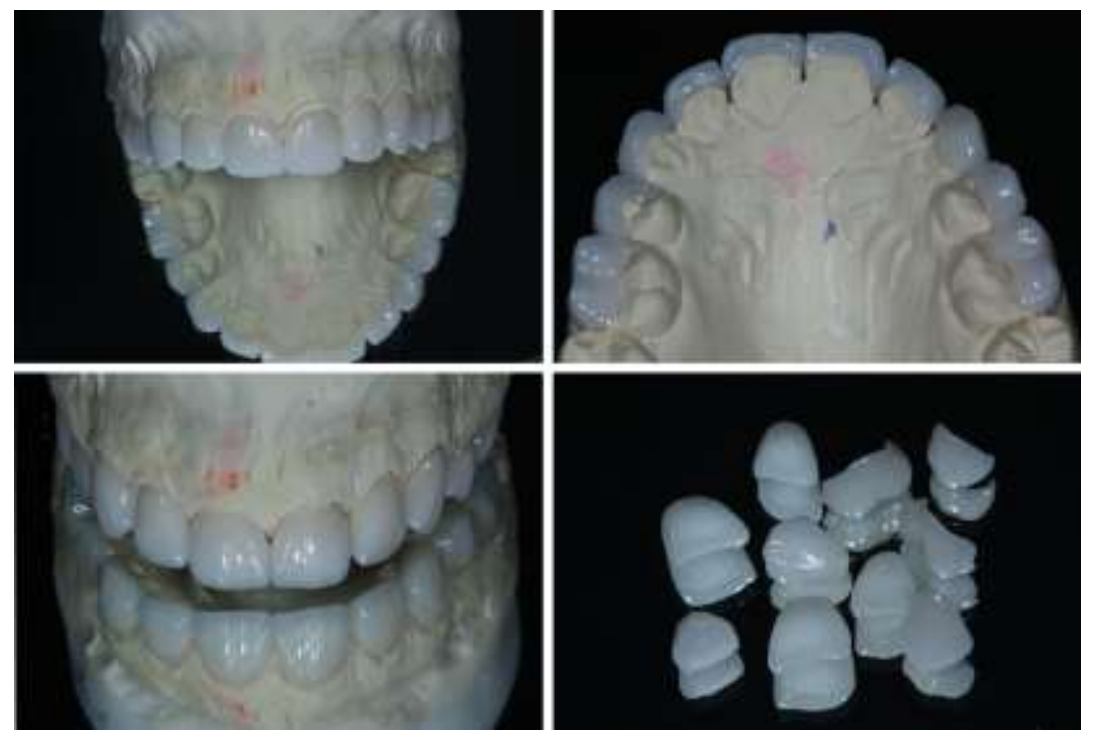

Figura 15. Peças protéticas finalizadas.

O substrato dental foi preparado utilizando ácido fosfórico a $37 \%$ durante 15 segundos, em seguida lavou-se e o excesso de água foi removido sem promover o ressecamento do substrato para a aplicação do adesivo dual Excite F (IvoclarVivadent), sem polimerização. As peças foram preenchidas com o cimento resinoso na cor previamente selecionada e os laminados foram mantidos em posição. Os excessos de cimento foram removidos com auxílio de pincéis e posteriormente foi realizada fotopolimerização por 40 segundos em cada face.
Após a polimerização, foram realizados ajustes oclusais nas posições de máxima intercuspidação habitual, protrusão e lateralidade direita e esquerda.Na Figura 16 e 17, pode-se observar o resultado obtido após a conclusão dos procedimentos restauradores.

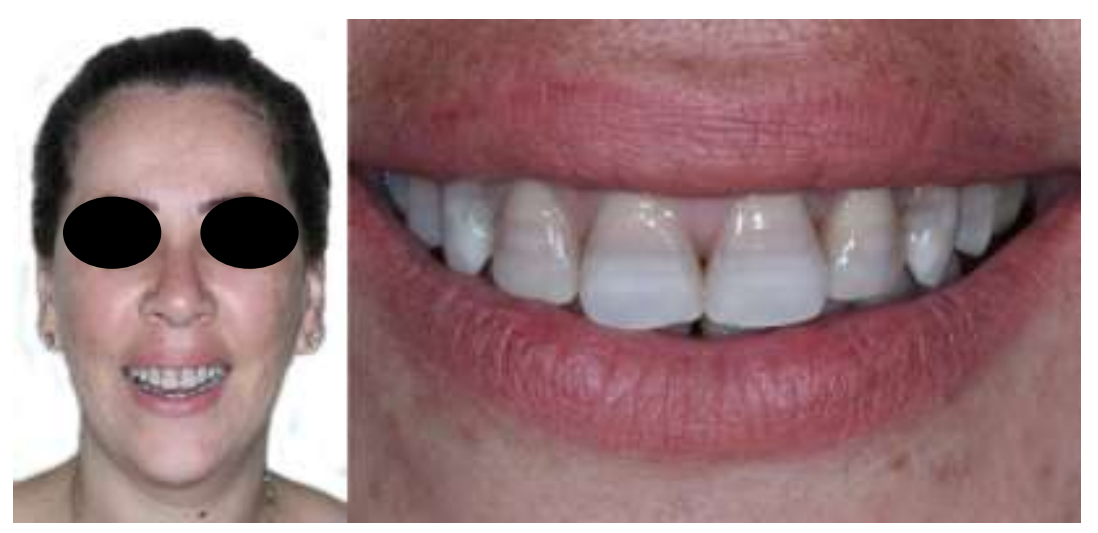

Figura 16. Caso inicial

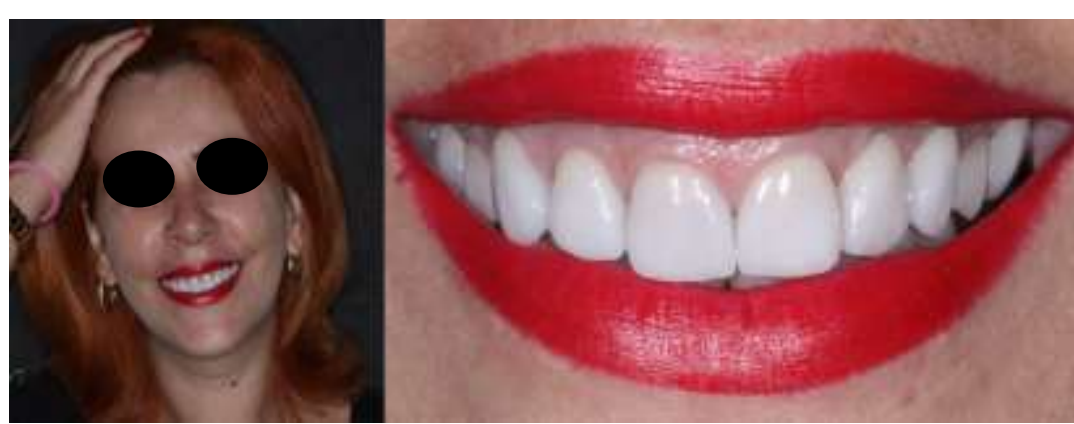

Figura 17. Caso finalizado

\section{DISCUSSÃO}

O conceito de restaurações estéticas com o menor desgaste possível já existe há muito tempo, mas com a evolução dos materiais cerâmicos, domínio das técnicas laboratoriais e melhor adesão das cerâmicas às estruturas dentais tem-se alcançado de forma crescente um excelente prognóstico estético e funcional com grande longevidade ${ }^{3-6}$.

No presente caso a paciente estava insatisfeita com seu sorriso por fugirem aos padrões de normalidade, uma vez que em decorrência do uso de tetraciclina durante a infância a paciente apresentava manchamentos amarelados, marrons e em tons de cinza, característicos de manchamento por tetraciclina grau III.Diante da situação apresentada, duas principais abordagens poderiam ser selecionadas: facetas diretas com o uso de resinas compostas ou o uso de facetas indiretas cerâmicas. Por sua ineficácia, o clareamento nesta classificação de manchamento não é a solução mais adequada ${ }^{7-8}$.

Clavijo, Kabbach ${ }^{9}$ (2013) relatou vantagens e desvantagens das facetas em resina composta, comparando-as a faceta de porcelana, citandocomo vantagens a necessidade de menor tempo clínico para sua confecção, a possibilidade de reparo, menor custo e por serem esteticamente aceitáveis. No entanto, como desvantagens as facetas em resinas compostas apresentam reduzida estabilidade de cor e brilho, além de menor resistência ao desgaste quando comparadas as facetas indiretas cerâmicas. 
As cerâmicas são materiais com alta resistência ao manchamento e ao desgaste, além de possuírem comprovada biocompatibilidade ${ }^{10} \mathrm{e}$ seus procedimentos laboratoriais para a confecção das restaurações cerâmicas exigem experiência, técnica, materiais e equipamentos diferenciados aumentando significativamente o custo ${ }^{11}$.

No entanto, fatores como resistência e estabilidade, alcançados pelas cerâmicas, são importantes nas reabilitações estéticas do sorriso, pois possibilitam aos pacientesa obtenção de um tratamento altamente estético e natural, com necessidade de menorintervenção ao longo dos anos no que diz respeito à manutenção ${ }^{12-14}$.

Diante dos fatores observados, no presente caso optou-se por laminados cerâmicos IPS e.max (IvoclarVivadent) por ser um sistema capaz de fornecer possibilidade de mascarar diferentes colorações do substrato dental, permitindo a mimetização da estrutura dental de forma natural. A escolha da técnica a ser utilizada e a escolha da cerâmica são imprescindíveis para o sucesso e longevidade do procedimento ${ }^{15}$.

Nos procedimentos adesivos, o esmalte é o substrato que permite um selamento melhor e mais estável, pois é altamente mineralizado, já a dentina tem bom selamento, contudo é aconselhável que o preparo em dentina seja associado a um cimento dual, garantindo adesividade segura inclusive nas áreas dedesgaste de maior profundidade, ou seja, com ou sem fotopolimerização ${ }^{16}$.

As cerâmicas feldspáticas são as que apresentam maior translucidez e naturalidade. Além destas, as cerâmicas reforçadas por dissilicato de lítio (IPS e.max) como no caso apresentado e podem ser utilizadas de duas formas: maquiadas ou estratificadas. No caso apresentado optou-se pelas maquiadas uma vez que o intuito principal era a beleza, a estética. $\mathrm{Na}$ cimentação, o condicionamento cerâmico preconizado pela técnica da cimentação adesiva, possibilitada pelo uso de um sistema ácido sensível, é considerado a melhor forma de obtenção de união químico-mecânica entre a estrutura dental e a superfície interna das peças protéticas metalfree.

Ao final dos procedimentos laminados cerâmicos indiretos, seguindo todo o protocolo clínico denotam extrema naturalidade, harmonia,estética e perspectiva de longevidade.

\section{CONCLUSÃO}

Através do presente caso clínico, pode-se concluir que a escolha de laminados cerâmicos IPS e.max (IvoclarVivadent) para a realização de restaurações em dentes manchados por tetraciclina grau III, foi o tratamento de melhor indicação para solucionar a estética do sorriso da paciente.
Entretanto, há de se destacar que um correto diagnóstico, um planejamento cuidadoso, execução criteriosa, conhecimento teórico, habilidades práticas e a escolha de um laminado cerâmico adequado e assertivo são imprescindíveis para que o resultado final tenha um aspecto natural e longevo, resultando em um sorriso de estética apreciável.

\section{REFERÊNCIAS}

1. Nathoo SA. The chemistry and mechanisms of extrinsic and intrinsic discoloration. J Am Dent Assoc. 1997; 128 Suppl:6S-10S.

2. Lacerda INL, Guimarães RP, Pompeu JGF, Menezes Filho PF, Silva CHV. Manchamento dentário por tetraciclina: como ocorre? Rev Fac Odontol Lins. 2009;21(2):41-6.

3. Horn HR. Porcelain laminate veneers bonded to etched enamel. Dent Clin North Am. 1983;27(4):671-84.

4. Magne P, Magne M, Belser U. Natural and restorative oral esthetics: part I: rationale and basic strategies for successful esthetic rehabilitations. J Esthet Restor Dent. 1993;5(4):161-73.

5. Kina S, Bruguera A. Laminados cerâmicos. Rev Dent Press Estética. 2006;3(2):45-69.

6. Fuso A, Bottino MA, Faria R. Faceta laminadas: funcionais, estéticas e preservadoras. Implant News. 2013;10(4):34-40.

7. Matis BA, Wang Y, Jiang T, Eckert GJ. Extended at-homebleaching of tetracycline-stained teeth with different concentrations of carbamide peroxide. Quintessence Int. 2002;33(9):645-55.

8. Caperhart K. Treating tetracycline staining in the adult dentition:a case report. Gen Dent. 2008;56(3):286-9.

9. Clavijo V, Kabbach W. Resinas compostas versus cerâmicas odontológicas. Clín Int J Braz Dent. 2013;9(1):16-21.

10. Radz GM. Porcelain laminate veneer therapy. Inside Dent. 2010;6(4):52-8.

11. Verde FAV, Pupo YM, Kose C, Gomes GM, Gomes JC. Previsibilidade com cerâmicas em dentes anteriores: IPS e.max Press e e.max Ceram. Rev Dental Press Estét. 2011;8(1):76-88.

12. Kifin PW, Barnes DM. The clinical longevity of porcelain veneers: a 48-month clinical evaluation. J Am Dent Assoc. 1998;129(6):747-52.

13. Shetty A, Kaiwar A, Shubhashini N, Ashwini P, Naveen D, Adarsha M, et al. Survival rates of porcelain laminate restoration based on different incisal preparation designs: an analysis. J Conserv Dent. 2011;14(1):10-5.

14. Layton DM, Clarke M. A Systematic review and meta-analysis of the survival of non-feldspathic porcelain veneers over 5 and 10 years. Int $\mathrm{J}$ Prosthodont. 2013;26(2):111-24. 
15. McLaren EA, Whiteman YY. Ceramics: rationale for material selection. Compend Contin Educ Dent. 2010;31(9):666-700.

16. Soares CJ, Soares PV, Pereira JC, Fonseca RB. Surface treatment protocols in the cementation process of ceramic and laboratory-processed composite restorations: a literature review. J Esthet Restor Dent. 2005;17(4):224-35.

\section{CONFLITO DE INTERESSES}

Os autores declaram não haver conflitos de interesse.

\section{AUTOR PARA CORRESPONDÊNCIA}

Adriana Cristina Zavanelli zavanelliac@foa.unesp.br 